\title{
Implications of ICD-9/10 CM Transition for Public Health Surveillance: Challenges, Opportunities, and Lessons Learned from Multiple Sectors of Public Health
}

\author{
Peter Hicks*1 and Atar Baer ${ }^{2}$ \\ ${ }^{1} \mathrm{CDC}$, Atlanta, GA, USA; ${ }^{2}$ Public Health Seattle And King County, Seattle, WA, USA
}

\section{Objective}

To provide a forum for local, state, federal, and international public health/ health care sectors to share promising practices and lessons learned in transitioning their organizations in the use of ICD-9 to ICD-10 codes for their respective surveillance activities.

\section{Introduction}

This roundtable will provide forum for a diverse set of representatives from the local, state, federal and international public health care sectors to share tools, resources, experiences, and promising practices regarding the potential impact of the transition on their surveillance activities. This forum will promote the sharing of lessons learned, foster collaborations, and facilitate the reuse of existing resources without having to "reinvent the wheel". It is hope that this roundtable will lay the ground-work for a more formal, collaborative, and sustainable venue within ISDS to aid in preparing the public health surveillance community for the coming ICD-9/10 CM transition.

\section{Methods}

The moderators will engage the participants in the discussion through dialogue in how their programs are currently using ICD-9 $\mathrm{CM}$ codes for surveillance and how the transition will impact their respective programs.

\section{Keywords \\ ICD-9; ICD-10; Transition}

*Peter Hicks

E-mail: phicks@cdc.gov 